\title{
Bronchopulmonary dysplasia as a predictor factor for motor alteration at 6 months corrected age in premature infants
}

\author{
Priscila Silveira Martins ${ }^{1}$, Rosane Reis de Mello², Kátia Silveira da Silva ${ }^{3}$
}

\begin{abstract}
Objective: The study aimed to assess bronchopulmonary dysplasia (BPD) as a predisposing factor for alteration in the psychomotor development index (PDI) in premature infants and verify the incidence of neuromotor alterations at 6 months corrected age. Method: This was a prospective cohort study that followed the neuromotor development of 152 very low birth weight premature infants, with psychomotor development index as the outcome. The study used the Bayley Scale of Infant Development at 6 months corrected age, and neurological examination. Results: Incidence of BPD was $13.2 \%(n=20)$. Logistic regression analysis showed an association between BPD and altered psychomotor development index (OR 3.98; 95\% Cl: 1.04-15.1) after adjusting for confounding variables. Neurological examination was altered in $67.1 \%$ of the 152 infants. Conclusion: Bronchopulmonary dysplasia acted as an independent predisposing factor for alteration in the psychomotor development index in premature infants at 6 months corrected age.
\end{abstract}

Key words: infant, premature, child development, psychomotor performance, risk factors, bronchopulmonary dysplasia.

Displasia broncopulmonar como fator predisponente para alterações motoras aos 6 meses em prematuros

\section{RESUMO}

Objetivo: Avaliar a displasia broncopulmonar (DBP) como fator predisponente para alteração no índice de desenvolvimento psicomotor em prematuros e verificar a incidência das alterações neuromotoras aos 6 meses de idade corrigida. Método: Estudo de coorte prospectivo que acompanhou o desenvolvimento neuromotor de 152 prematuros de muito baixo peso, cujo desfecho foi o desenvolvimento psicomotor. Utilizou-se a Bayley Scale of Infant Development aos 6 meses de idade corrigida e exame neurológico. Resultados: A incidência de DBP foi de 13,2\% (n=20). A análise de regressão logística mostrou associação entre a DBP e alteração no índice de desenvolvimento psicomotor (RC 3,98 IC 95\%:1,04$15,1)$ após ajuste para as variáveis de confundimento. $O$ exame neurológico apresentouse alterado em 67,1\% das 152 crianças. Conclusão: A displasia broncopulmonar atuou como fator predisponente independente para alteração no índice de desenvolvimento

Correspondence Rosane Reis de Mello Rua Eurico Cruz 23 / 301 22461-200 Rio de Janeiro RJ - Brasil E-mail: rosanemello@gmail.com rmello@iff.fiocruz.br

\section{Support}

PAPES IV - Fundação Oswaldo Cruz e Conselho Nacional de Desenvolvimento Científico e Tecnológico (CNPq)

Received 02 November 2009 Received in final form 14 April 2010 Accepted 22 April 2010 psicomotor em prematuros aos 6 meses de idade corrigida.

Palavras-chave: lactente, prematuro, desenvolvimento infantil, desempenho psicomotor, fatores de risco, displasia broncopulmonar.

In recent decades, technological development has fostered an increase in the survival of newborns with progressively lower gestational age and birth weight, a trend that has been even more significant at the limits of viability ${ }^{1}$. This has resulted 
in more children exposed to important risk factors for altered psychomotor development.

Systematic assessment of motor development serves as an instrument for early detection of neurological alterations whose adequate management can minimize the sequelae, providing better quality of life for children and their families. Various scales assess motor development in infants, with the Bayley Scale of Infant Development $(B S I D)^{2}$ as the most widely used in monitoring infants at risk, as well as in research in the field of child health ${ }^{3-5}$.

The BSID assesses the progressive functional development of children from one to 42 months of age, posing specific tasks with increasing complexity, and is divided into three sub-scales (mental, psychomotor, and behavioral). The psychomotor scale of the BSID assesses gross and fine motor development and furnishes a score called the psychomotor development index (PDI), with a mean of 100 and a standard deviation of 15 .

Bronchopulmonary dysplasia (BPD), whose etiology involves use of prolonged mechanical ventilation and oxygen therapy, is closely related to prematurity ${ }^{6}$. There is no consensus in the literature as to the relative contribution of this diagnosis to motor development ${ }^{6,7}$. Comorbidities affecting neurological prognosis in this population require an adequate methodology to control confounding factors and clarify the issue.

The aim of the current study was to assess bronchopulmonary dysplasia as a risk factor for alteration in the psychomotor development index in very low birth weight premature infants and verify the incidence of neuromotor alterations at 6 months corrected age.

\section{METHOD}

This was a prospective cohort study that assessed premature infants (gestational age less than 37 weeks) with birth weight less than $1500 \mathrm{~g}$, born from January 2004 to June 2008. The sample excluded newborns with congenital malformations, congenital infections, genetic syndromes, or severe sensory deficits that could affect motor development, and deaths occurring before 6 months corrected age. Corrected age was calculated by subtracting from the chronological age the number of weeks needed for the child to reach term (40 weeks gestational age).

According to National Institutes of Health Consensus, bronchopulmonary dysplasia was defined as a clinical condition of supplemental oxygen need at 36 weeks corrected age ${ }^{8}$.

The infants were submitted to monthly clinical evaluations $^{9}$ that included motor examination using the method described by Amiel Tyson and Grenier ${ }^{10}$. This examination method includes muscle tone assessment in the various body segments (cervical, axial, upper and lower limbs, and shoulder girdle), reflexes, asymmetries, and observation of motor milestones. Neurological examination at 6 months was considered altered when it presented any alteration in tonus of the body segments or altered reflexes or asymmetries. Delayed motor development was defined as infants that failed to acquire adequate motor milestones for 6 months corrected age, based on the clinical and neurological assessment ${ }^{10-12}$ and the results of the Denver II test ${ }^{13}$.

At 6 months corrected age, the Bayley Scale of Infant Development, $2^{\text {nd }}$ Edition (BSID II) ${ }^{2}$ was applied by two skilled psychologists, previously trained, who were blinded as to the perinatal and neonatal history of these premature infants. Inter-observer reliability for psychomotor development index (PDI), measured by the intraclass correlation coefficient (ICC), was 0.91 (95\% CI: 0.76-0.97). The infants were classified as either normal PDI (score $\geq 85)$ or altered PDI $(<85)$. The study's outcome variable was the psychomotor development index.

Data collection was prospective, which allowed obtaining information on all the target variables. The outcome was not known when the data on exposure and other risk factors were collected. Data on socioeconomic conditions, the index pregnancy, delivery, and neonatal period were obtained through interviews with the mothers and consultation of patient charts.

When patients failed to appear for two consecutive appointments, the researchers contacted the family by telephone to obtain information on the reason for nonattendance and to reinforce the importance of appearing for the subsequent appointments.

The study was approved by the Institutional Review Board of the Fernandes Figueira Institute, Rio de Janeiro, Brazil. Informed consent was requested from at least one parent or guardian, both for participating in the study and for performing the evaluations and other procedures.

Sample size calculation was based on a hypothetical 70\% incidence of altered motor development in the infants with BPD and 35\% in the group without the disease $^{7,14}$. Using a $95 \%$ confidence interval and power of $80 \%, 21$ infants would be needed in the exposed group (BPD) and 126 in the unexposed group.

Data analysis used EpiInfo version 3.5 (Centers for Disease Control and Prevention, 2008). Statistical tests were used for differences in means (F-statistics or Kruskal Wallis) and proportions (chi-square), and level of significance was set at 0.05 . The incidence rates were calculated in the study population for BPD, altered PDI, and principal alterations in the neurological examination at 6 months corrected age.

The association between the exposure variable (BPD) and the outcome variable (PDI) was verified by the odds ratio (OR). The population's neonatal and demographic characteristics were investigated as potential confound- 
ers, based on the association between the covariables and the exposure and outcome. The variation was investigated between the magnitude of the association between BPD and altered PDI when adjusted for each of these study variables, defined as potential confounders in the previous stage. Variables whose adjustment caused a change greater than $10 \%$ in the risk of the main exposure variable (BPD) were selected for the multivariate model (logistic regression). The presence of interaction between the covariables and exposure was also investigated.

\section{RESULTS}

From January 2004 to June 2008, 301 premature infants with birth weight less than $1500 \mathrm{~g}$ were admitted to the Neonatal Intensive Care unit at the Fernandes Figueira Institute. Of these, 109 were excluded (51 infants with malformations or congenital infections, born in different hospitals, 53 neonatal deaths, 4 deaths after discharge, and one infant with bilateral visual impairment). A total of 192 infants met the inclusion criteria. During the first 6 months of follow-up there were 40 losses (20.8\%) due to missed appointments, despite the team's effort to track and retrieve this group of infants. The final sample consisted of 152 infants that completed the BSID II evaluation, with a mean age of 6.5 months (SD: 0.9), representing $79.2 \%$ of the population that met the inclusion crite- ria. There was no difference in the neonatal characteristics between the infants that underwent the BSID II evaluation and the losses to follow-up.

Table 1 shows the study population's characteristics. As for neurological complications, only 1 patient $(0.7 \%)$ presented periventricular leukomalacia and 33 (21.7\%) presented intracranial hemorrhage (ICH), with the following distribution in severity: 24 patients with grade I (15.8\%); 1 grade II ( $0.7 \%)$, and 5 grade III (3.3\%). Three patients (2.0\%) presented parenchymal hemorrhage (grade IV).

Incidence of BPD in the study group was $13.2 \%(\mathrm{n}=20)$, and these infants were classified as presenting the moderate or severe forms of the disease, since they still required oxygen therapy at 36 weeks corrected age ${ }^{8}$.

Table 1 shows the characteristics of the infants with $\mathrm{BPD}$, with a high incidence of patent ductus arteriosus (PDA).

Among the group with BPD, 19 patients (95\%) required mechanical ventilation during the neonatal period, with a mean duration of 18 days (SD 19 days; median 8 ). Mean time on oxygen was 80 days (SD: 47.3 days; median: 67 days).

Neonatal neurological complications in newborns with BPD were intracranial hemorrhage in 9 patients, of which 5 were grade I (25.0\%), 1 grade II (5.0\%), and 3 grade III (15.0\%). No infant presented parenchymal hem-

Table 1. Characteristics of very low birth weight premature infants born from 2004 to 2008, Fernandes Figueira Institute, Rio de Janeiro, Brazil.

\begin{tabular}{|c|c|c|c|}
\hline Characteristics & Total $(n=152)$ & $\operatorname{BPD}(n=20)$ & No BPD $(n=132)$ \\
\hline \multicolumn{4}{|l|}{ Birth weight (g) } \\
\hline Mean (DP) & $1122(240.2)$ & $984(265)$ & $1143(230)$ \\
\hline Median & 1150 & 975 & 1165 \\
\hline \multicolumn{4}{|l|}{ Gestational age (weeks) } \\
\hline Mean (DP) & $29(2)$ & $28(2)$ & $30(2)$ \\
\hline Median & 29 & 28 & 30 \\
\hline Male gender-n (\%) & $73(48.0)$ & $16(80.0)$ & $57(43.2)$ \\
\hline Female gender-n (\%) & $79(52.0)$ & $4(20.0)$ & $75(56.8)$ \\
\hline Assisted ventilation-n (\%) & $91(59.9)$ & $19(95.0)$ & $72(54.5)$ \\
\hline \multicolumn{4}{|l|}{ Time on assisted ventilation } \\
\hline Mean (days) & $7.8(12)$ & $17.7(19.5)$ & $3.5(7.3)$ \\
\hline Median (days) & 2.0 & 7.8 & 0.79 \\
\hline \multicolumn{4}{|l|}{ Time on oxygentherapy (days) } \\
\hline Mean & $24.5(33.0)$ & $80.9(47.4)$ & $13.4(17.5)$ \\
\hline Median & 9.0 & 67.0 & 5.5 \\
\hline Neonatal pneumonia-n (\%) & $18(11.8)$ & $7(35.0)$ & $11(8.3)$ \\
\hline Patent ductus arteriosus-n (\%) & $66(44.3)$ & $15(75.0)$ & $51(39.5)$ \\
\hline Intracranial hemorrhage-n (\%) & $33(21.7)$ & $9(45.0)$ & $24(18.2)$ \\
\hline Small for gestational age-n (\%) & $58(34.4)$ & $7(35.0)$ & $51(38.9)$ \\
\hline
\end{tabular}

BPD: bronchopulmonary dysplasia; SD: standard deviation; No BPD: without bronchopulmonary dysplasia. 
Table 2. Means of psychomotor development index in children with neuromotor alteration at 6 months corrected age with and without bronchopulmonary dysplasia.

\begin{tabular}{|c|c|c|c|c|}
\hline \multirow[b]{3}{*}{ Neuromotor alterations at 6 months corrected age } & \multicolumn{2}{|c|}{$\operatorname{BPD}(n=20)$} & \multirow{2}{*}{\multicolumn{2}{|c|}{$\frac{\text { No BPD }(n=132)}{\text { PDI }}$}} \\
\hline & \multicolumn{2}{|c|}{ PDI } & & \\
\hline & $n(\%)^{* *}$ & Mean (SD) & $\mathrm{n}(\%)^{* * *}$ & Mean (SD) \\
\hline Delayed acquisition of motor milestone* & $17(85.0)$ & $68.3(13.8)$ & $68(51.5)$ & $76.6(15.0)$ \\
\hline Asymmetry & $6(30.0)$ & $71.7(12.6)$ & $22(16.7)$ & $80.0(15.9)$ \\
\hline Lower limb hypertonia & $9(45.0)$ & $70.6(12.8)$ & $30(22.7)$ & $77.4(17.0)$ \\
\hline Axial hypotonia* & $12(60.0)$ & $65.3(12.9)$ & $54(40.9)$ & $78.6(14.6)$ \\
\hline
\end{tabular}

*Statistically significant difference in PDI mean between BPD and no BPD infants - $p<0.05$; ** n: number of children with alteration on neuromotor exam at 6 months corrected age and with bronchopulmonary dysplasia; ${ }^{* *} n$ : number of children with alteration on neuromotor exam at 6 months corrected age and without bronchopulmonary dysplasia; PDI: psychomotor development index; BPD: bronchopulmonary dysplasia; SD: standard deviation; No BPD: without bronchopulmonary dysplasia.

Table 3. Association between bronchopulmonary dysplasia and altered psychomotor development index, adjusted for the selected variables.

\begin{tabular}{|c|c|c|c|c|}
\hline & Crude odds ratio & $95 \% \mathrm{Cl}$ & Adjusted odds ratio* & $95 \% \mathrm{Cl}$ \\
\hline $\mathrm{BPD}$ & 6.8 & $1.9-24.3$ & 3.98 & $1.04-15.1$ \\
\hline
\end{tabular}

orrhage. There was a significant difference between the two groups in the incidence of $\mathrm{ICH}$, which was higher in patients with BPD ( $45 \%$ vs. $18 \%$; p: 0.007 ).

Incidence of altered PDI at 6 months corrected age $(\mathrm{PDI}<85)$ was $90.0 \%(\mathrm{n}=18)$ in patients with $\mathrm{BPD}$ and 47.7 $\%(n=63)$ in patients without BPD, a statistically significant difference ( $\mathrm{p}=0.0004)$.

Mean psychomotor development index (PDI) for the entire study group was 82.3 (SD: 17.0). There was a significant difference in mean PDI between children with BPD (69.7; SD: 13.2) and those without (84.2; SD: 16.7).

As for neurological examination, $67.1 \%$ of the 152 infants presented alterations at 6 months corrected age. At this age, $90 \%$ of infants with BPD and $63.6 \%$ of those without BPD presented alterations. The most frequent alterations in the whole study group were delayed acquisition of motor milestones (56\%), axial hypotonia in $43.4 \%$, lower limb hypertonia in $25.7 \%$, and asymmetry in $18.4 \%$. In children with BPD, the observed alterations (Table 2) were delayed acquisition of motor milestones (85\%), axial hypotonia (60\%), and lower limb hypertonia (45\%), while the latter were non-concurrent. Hypertonia of upper limbs occurred in 2 infants with BPD (10\%). Infants with BPD showed a significantly higher incidence of lower limb hypertonia than those without BPD ( $\mathrm{p}=0.03)$. Among the children with this alteration and BPD, 3 had intracranial hemorrhage, 4 were less than 28 weeks gestational age and 4 were small for gestational age. Table 2 shows the means of psychomotor development index in children with neuromotor alteration at 6 months corrected age, with and without BPD.The need for motor physi- cal therapy was more frequent among children with BPD ( $55 \%$ vs. $36.8 \%$; $\mathrm{p}=0.07$ ).

Among children with altered PDI, axial hypotonia and lower limb hypertonia were the most frequent neurological alterations $(53.1 \%$ and $33.3 \%$ of these children, respectively).

After adjusting for confounding variables, the following variables were selected by the multivariate logistic model: bronchopulmonary dysplasia, intracranial hemorrhage, male gender, and patent ductus arteriosus. After controlling for these risk factors, BPD (principal exposure) remained significantly associated with altered psychomotor development index (Table 3).

No interaction was identified between these variables and the principal exposure.

\section{DISCUSSION}

The incidence of bronchopulmonary dysplasia in this study was consistent with data from the literature ${ }^{6}$. Patients with BPD showed a higher incidence of intracranial hemorrhage than those without BPD. Although the literature does not show a direct relationship between these two clinical conditions, there is an association between $\mathrm{ICH}$ and other frequent complications in this population, like hypoxia, use of mechanical ventilation ${ }^{15}$, and patent ductus arteriosus ${ }^{16}$.

A significant percentage of the infants presented altered psychomotor development index at 6 months corrected age, both those with BPD (90.0\%) and those without (47.7\%). The high percentage of altered PDI may be due to the cutoff point used here (85), which also aimed 
to detect patients with mildly delayed performance. If one considers a PDI less than 70, 45\% (9) of the patients with BPD and 19.7\% (26) of the patients without BPD would be identified as having altered PDI (results not shown).

In relation to neurological examination, infants with BPD showed significantly more delay in achieving motor milestones and more lower limb hypertonia as compared to those without BPD. The need for physical therapy was significantly associated with BPD.

Part of the observed alterations may be due to socalled transient neurological abnormalities, which can be detected in 40 to $80 \%$ of premature infants in the first year of life, disappearing in the months thereafter ${ }^{17}$. However, despite the risk of overestimating these findings, some characteristics highlight the need for early diagnosis of neuromotor alterations. First, neuroplasticity is more pronounced in the first months of life, so that the impact of treatment is greater in younger infants. Als et al. ${ }^{18}$ investigated the effects of early experience on cerebral function and structure, using electroencephalography and nuclear magnetic resonance. A group of 30 premature infants without risk factors for neurodevelopmental alterations participated in a clinical trial to assess the effect of an early neonatal stimulation approach (Newborn Individualized Developmental Care and Assessment Program, NIDCAP). The subgroup exposed to NIDCAP showed better function and greater maturity of nerve fibers as compared to the control group. Gianní et al. ${ }^{19}$ identified, at 36 months corrected age, beneficial effects for the development of very low birth weight premature infants submitted to an intervention program beginning at 3 months of age.

Caution should be used in diagnosing a neurological condition like cerebral palsy at very early ages, and the diagnosis should only be confirmed in the presence of neurological signs that persist beyond 24 months of age. A multicenter European study entitled Surveillance of Cerebral Palsy in Europe ${ }^{20}$, recommends that the definitive diagnosis of cerebral palsy should not be made before 3 years of age. However, this does not rule out an early and more effective therapeutic approach to a motor alteration before the diagnosis is confirmed.

The importance of early diagnosis of neuromotor alterations is also emphasized by recent findings that correlate these alterations with difficulties in school. Jeyaseelan et al. ${ }^{21}$ followed a cohort of extremely premature infants and found a significant association between minor motor signs at 24 months of age and difficulties with attention from 7 to 9 years of age. Although early motor alterations have not been correlated with cognitive dysfunctions, these findings suggest that motor and cognitive development may be more interrelated than previously suspected. The cerebellum and prefrontal cortex, which are important for motor and cognitive development, may be involved in this process. At any rate, these children need to continue to have their neurodevelopment monitored in order to identify which of them will present persistent neurological symptoms.

Perlman and Volpe ${ }^{22}$, described the neonatal neurological characteristics of infants with severe BPD that were similar to extrapyramidal movements seen in older children. These patients presented chronic hypoxemia, hypercapnia, bronchospasm, and malnutrition. The abnormal movements reported by these authors began developing in the third month of life and involved the limbs, cervical region, trunk, and mouth and tongue. This motor syndrome was exacerbated during episodes of respiratory failure and attenuated during sleep. Neuropathological studies in one of the infants showed neuronal loss in structures of the basal ganglia.

Multivariate analysis showed that BPD increased the incidence of altered psychomotor development index, independently of other risk factors. Infants with BPD showed four-fold odds of presenting altered PDI at 6 months corrected age as compared to infants without BPD.

The role of BPD in the complex process of neurodevelopment is controversial in the literature. Some authors contend that this respiratory condition leads to intermittent episodes of hypoxia and acts on motor development as an independent factor ${ }^{23}$. However, others affirm that the associated complications, like intraventricular hemorrhage or leukomalacia, are the true determinants of neurodevelopment ${ }^{24-26}$. In our study, in the multivariate analysis, although cerebral hemorrhage showed a risk of 1.7 , the association was not statistically significant (results not shown).

Burns et al. ${ }^{14}$ compared 64 children with BPD and 53 controls and concluded that at 8 months, children with BPD showed significant motor delay, and that at 2 years, although the delay was less pronounced, relevant differences remained between the two groups in terms of motor control and balance. However, after adjusting for other factors (periventricular hemorrhage and ventricular dilatation), the difference was not significant.

Majnemer et al. ${ }^{7}$ found an association between severe BPD (supplementary oxygen at home) and presence of neurological alterations at school age. Two groups (BPD and controls) with 27 subjects each were followed prospectively and compared at 9 years of age, showing a much higher incidence of neurological abnormalities in the BPD group (including subtle neurological signs, cerebral palsy, microcephaly, and behavioral alterations). More than 50\% of the BPD patient cohort in use of home oxygen displayed difficulties in gross and fine motor skills. In our population, only one child was using home oxygen at 6 months corrected age.

Short et al. ${ }^{27}$ also studied the long-term consequenc- 
es of BPD, prospectively following 2 groups of 98 and 75 very low birth weight children (with and without $B P D$, respectively) and 99 term children at 8 years of age. The BPD group showed deficits in various skills, like IQ, math, reading, and gross motor functions. The authors concluded that BPD had adverse effects on cognitive and scholastic prognosis, beyond the effect of low birth weight.

When monitoring very low birth weight newborns, those with moderate to severe BPD should be subject to greater surveillance of their neuromotor development, and during birthstay hospitalization they should receive special care targeted to posture and handling. When alterations are identified, early interventions are recommended to prevent future neuromotor deficits, even if part of these alterations may be transient.

In conclusion, bronchopulmonary dysplasia acted as an independent risk factor for motor development in premature infants at 6 months corrected age. Children with this diagnosis showed four-fold odds of altered psychomotor development index at this age.

ACKNOWLEDGMENT - We thank the psychologists Ana Beatriz Reis and Juliana Verçosa Delamônica for application the Bayley Scale of Infant Development.

\section{REFERENCES}

1. Hintz SR, Kendrick DE, Vohr BR, Poole K, Higgins RD. Changes in the neurodevelopmental outcomes at 18 to 22 months' corrected age among infants of less than 25 weeks' gestational age born in 1993-1999. Pediatrics 2005;115:1645-1650.

2. Bayley N. Bayley scales of infant development. $2^{\text {nd }}$ Ed. San Antonio: The Psychological Corporation, 1993.

3. Goto MMF, Gonçalves VMG, Netto AA, Morcillo AM, Moura-Ribeiro MVL. Neurodevelopment of full-term small-for-gestational age infants in the second month of life. Arq Neuropsiquiatr 2005;63:75-82.

4. Hack M, Wilson-Costello D, Friedman H, Taylor GH, Schluchter M, Fanaroff AA. Neurodevelopment and predictors of outcomes of children with birth weights of less than 1000g: 1992-1995. Arch Pediatr Adolesc Med 2000;154:725-731.

5. Mello RR, Dutra MV, Silva KS, Lopes JM. The predictive value of neurological assessment and neonatal cranial ultrasonography with respect to the development of very low birth weight premature infants. Rev Saúde Pública 1998;32:420-429.

6. Monte LFV, Silva Filho LFV, Miyoshi MH, Rozov T. Bronchopulmonary dysplasia. J Pediatr (Rio J) 2005;81:99-110.

7. Majnemer A, Riley P, Shevell M, Birnbaum R, Greenstone H. Severe bronchopulmonary dysplasia increases risk for later neurological and motor sequelae in preterm suvivors. Dev Med Child Neurol 2000;42:53-60.
8. Jobe AH, Bancalari E. Bronchopulmonary dysplasia. Am J Respir Crit Care Med 2001;163:1723-1729.

9. Mello RR, Silva KS, de Rodrigues MCC, Chalfun G, Ferreira RC, Delamônica JVR. Predictive factors for neuromotor abnormalities at the corrected age of 12 months in very low birth weight premature infants. Arq Neuropsiquiatr 2009;67:235-241.

10. Amiel Tyson C, Grenier A, Neurological assessment during the first year of life. New York: Oxford University Press, 1986.

11. Holt KS. Development in the first year. In: Holt KS (Ed). Child development: diagnosis and assessment. London: Butterworth-Heinemann, 1991:70-102.

12. Restiffe AP, Gherpelli JLD. Comparison of chronological and corrected ages in the gross motor assessment of low-risk preterm infants during the first year of life. Arq Neurosiquiatr 2006;64:418-425.

13. Frankenburg WK, Dodds JB, Archer P, Sharir H, Breusnich. The Denver II: a major revision and restandartization of the Denver developmental screening test. Pediatrics 1992;89: 91-97.

14. Burns Y, Gray P, O'Callaghan M. Bronchopulmonary dysplasia: a comparative study of motor development to two years of age. Aust J Physiother 1997:43:19-25

15. Kadri H, Mawla AA, Kazah J. The incidence, timing and predisposing factors of germinal matrix and intraventricular hemorrhage $(\mathrm{GMH} / \mathrm{IVH})$ in preterm neonates. Childs Nerv Sys 2006;22:1086-1090

16. Couser RJ, Hoekstra RE, Ferrara TB, Wright GB, Cabalka AK, Connet JE. Neurodevelopmental follow-up at 36 months corrected age of preterm infants treated with prophylactic indomethacin. Arch Pediatr Adolesc Med 2000;154:598-602

17. Rugolo LM. Growth and developmental outcomes of extremely preterm infants. J Pediatr (Rio J) 2005;81(Suppl):S101-S110.

18. Als H, Duffy FH, McAnulty GB, et al. Early experience alters brain function Pediatrics 2004;113:846-857.

19. Gianní ML, Picciolini O, Ravasi M, Gardon L, Vegni C. The effects of an early developmental mother-child intervention program on neurodevelopment outcome in very low birth weight infants: a pilot study. Early Hum Dev 2006;82:691-695.

20. Surveillance of Cerebral Palsy in Europe (SCPE). Prevalence and characteristics of children with cerebral palsy in Europe. Dev Med Child Neurol 2002:44:633-640.

21. Jeyaseelan D, O'Callaghan M, Neulinger K, Shum D, Burns Y. The association between early minor motor difficulties in extreme low birth weight infants and school age attentional difficulties. Early Hum Dev 2006;82:249-255.

22. Perlman JM, Volpe JJ. Movement disorder of premature infants with severe bronchopulmonary dysplasia: a new syndrome. Pediatrics 1989;84:215-218.

23. Anderson AE, Wildin SR, Woodside $M$, et al. Severity of medical and neurologic complications as a determinant of neurodevelopmental outcome at 6 and 12 months in very low birth weight infants. J Child Neurol 1996; 11:215-219.

24. Leonard CH, Clyman RI, Piecuch RE, Juster RP, Ballard RA, Behle MB. Effect of medical and social risk factors on outcome of prematurity and very low birth weight. J Pediatr 1990;116:620-626.

25. Luchi JM, Bennet FC, Jackson JC. Predictors of neurodevelopmenta outcome following bronchopulmonary dysplasia. Am J Dis Child 1991;145: 813-817.

26. Sauve RS, Singhal N. Long-term morbidity of infants with bronchopulmonary dysplasia. Pediatrics 1985;76:725-733.

27. Short EJ, Klein NK, Lewis BA, et al. Cognitive and academic consequences of bronchopulmonary dysplasia and very low birth weight: 8-year-old outcomes. Pediatrics 2003:112:359- 366 